\title{
Concentrated Solar Thermal (CST) Systemfor Fuelwood Replacement and Household Water Sanitation in Developing Countries
}

\author{
Olutoye P. Akinjiola ${ }^{1} \&$ Uthamalingam Balu Balachandran ${ }^{2}$ \\ ${ }^{1}$ Psage Research, LLC, USA \\ ${ }^{2}$ Energy Systems Division, Argonne National Laboratory, Argonne, USA \\ Correspondence: Uthamalingam (Balu) Balachandran, Energy Systems Division, Argonne National Laboratory, \\ Argonne, IL 60439, USA. Tel: 630-252-4250. E-mail: balu@anl.gov
}

Received: February 28, 2012 Accepted: April 26, 2012 Online Published: May 17, 2012

doi:10.5539/jsd.v5n6p25

URL: http://dx.doi.org/10.5539/jsd.v5n6p25

The research is sponsored by the U.S. Department of Energy, under Contract Number DE-AC02-06CH11357

\begin{abstract}
Concentrated Solar Thermal (CST) is a proven renewable energy technology that harnesses solar irradiation in its most primitive form. This technology with roots in ancient history is growing at a fast pace in recent times. Developing countries could use CST to solve fundamental human-needs challenges, such as for the substitution of fuelwood and the treatment of water for household use. This paper proposes a conceptual design for a standardized modular CST for these applications in developing countries. A modular-designed parabolic CST with an aperture area of $7.5 \mathrm{~m}^{2}$ is adequate to provide enough solar thermal energy to replace the fuelwood need ( 5 tons/yr) or to pasteurize the minimum daily water requirement (2500 liters) for a household. Critical parameters of the CST are discussed and an affordable solid thermal storage is recommended to be used as a backup when sunlight is unavailable. A funding program that includes in-country resources and external funding will be needed to sustain the development and wide spread adaptation of this technology.
\end{abstract}

Keywords: Concentrated Solar Power (CSP), Concentrated Solar Thermal (CST), solar, sustainable development

\section{Introduction}

When solar power is discussed it is the image of solar panels generating electricity that comes to the mind of most people. This form of solar energy harnessing is called photovoltaic (PV-Solar), whereby solar radiation is converted to electricity. While PV-Solar was not commercialized until the $1950 \mathrm{~s}$, devising means to convert solar to thermal (heat) energy has been around since the beginning of time. Solar energy can be harnessed to generate not only thermal energy, but also electricity or any other form of energy. Concentrated solar thermal (CST) is a method whereby the solar radiation that falls on a given surface is focused on a smaller surface to increase its intensity. It is said that, in $212 \mathrm{BC}$, Archimedes employed polished bronze shields to focus sunlight to set fire to wooden ships from the Roman Empire which were besieging Syracuse. Thus, the concept of CST is not entirely new even in developing countries. The technology could be as simple as Archimedes's arrangement and could be as sophisticated as the 354 MW Solar Energy Generating System (SEGS, in Mojave Desert, California) which is the largest solar power plant in the world (Cohen, 1999). CST when coupled with power generation is called concentrated solar power (CSP), but oftentimes CSP is used as a generic abbreviation for both technologies. In whatever method, CSP, CST, or PV-Solar, the energy derived from the sun is renewable when compared to fossil fuel. It is clean and non-polluting, and has no carbon emissions that contribute to climate change.

Both developed and developing countries could benefit from the abundance of solar energy for electricity generation and industrial applications. Developed countries are already commercializing CSP at a rapid pace, and the market has seen about $740 \mathrm{MW}$ of generating capacity added between 2007 and the end of 2010. CSP global capacity is about $1095 \mathrm{MW}$ as of 2010. Spain alone is expected to add a total new capacity of $1789 \mathrm{MW}$ by the end of 2013 while the US will add $1.5 \mathrm{GW}$ of parabolic trough and power-tower plants by 2012 and has contracts signed for at least another $7.8 \mathrm{GW}$ (Sawin et al., 2011). While developing countries could emulate those that are advanced in employing CSP for electricity, it is the harnessing of solar energy to solve 
fundamental human-needs problems that is most urgent and affordable. Such basic applications of CST are simple and scalable, unlike CSP, which is only economical for large - scale applications. Some of the challenges facing developing countries that could be solved with CST are replacement of fuelwood and provision of clean drinking water. A conceptual design for a standardized modular CST for these applications in developing countries is presented in this paper.

\section{Background}

\subsection{How Much Solar Energy is Available?}

The sun irradiates 1.366 kilowatts per meter squared on to the earth, though not all this energy is actually available at every location at all times for several reasons: clouds, inclination of the earth and its rotation, etc. To put the potential supply of energy from the sun in perspective, Knies of Desertec Foundation (Knies, 2012) claims that within six hours the deserts receive more energy from the sun than humankind consumes within a year, and that all fossil fuels (oil and gas) known and expected are equivalent to 40 weeks of the sun's irradiation (Knies, 2012).

For Africa, the average solar irradiation/day is given in Figure 1. There is enough solar irradiation to be tapped within each locality to meet the energy requirements of any developing country. The current limitation is the dissemination of the appropriate technology that could be used to harness solar energy even for the immediate goals of these countries. The average direct normal irradiance (DNI) for Nigeria is $5.5 \mathrm{kWh} / \mathrm{m}^{2} /$ day; Ghana, 5.2 $\mathrm{kWh} / \mathrm{m}^{2} /$ day; and Burundi, $4.5 \mathrm{kWh} / \mathrm{m}^{2} /$ day. In each of these countries less than $0.1 \%$ of the land area is needed to generate enough solar energy for what the projected annual energy consumption will be in 30years (Sambo, 2008).

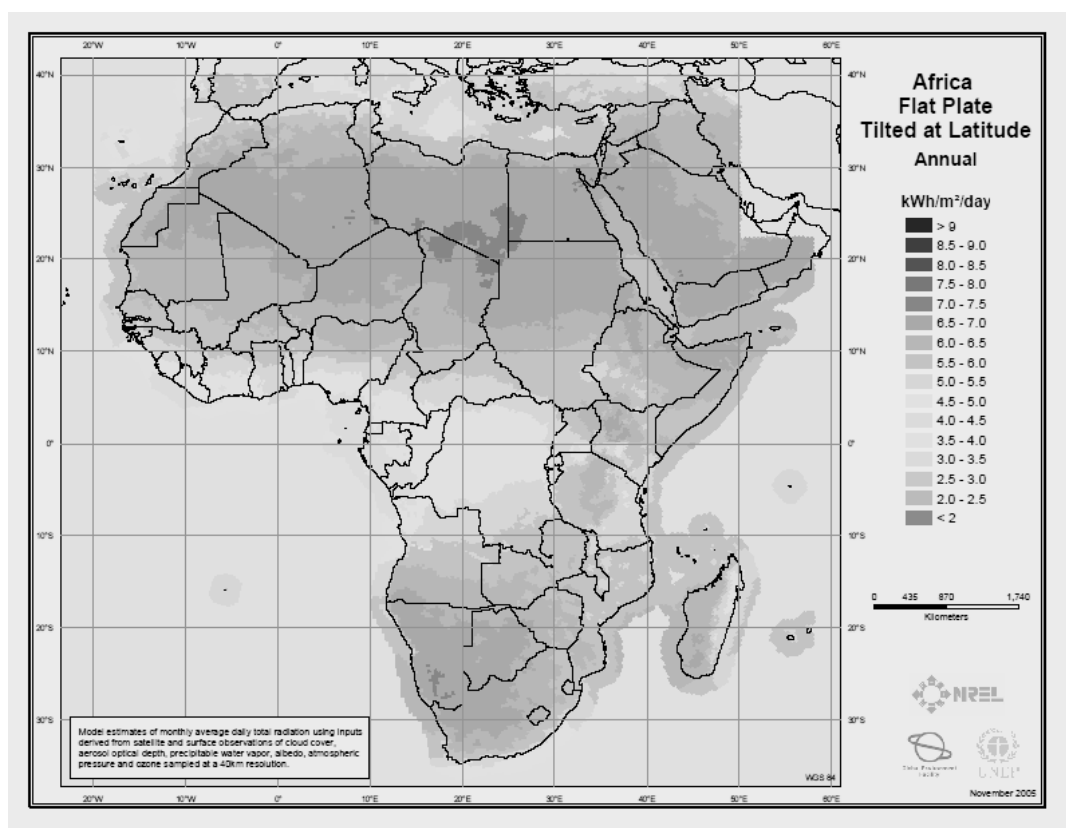

Figure 1. Yearly average Daily Solar Irradiation (DNI) (Solar and Wind Energy Assessment, 2005)

The focus here is on CST for fuelwood replacement and the production of safe drinking water because these constitute major needs of developing countries. In addition, the harnessing technologies are simple and affordable, and could be implemented without any significant lead times.

\subsection{Solar Energy as Clean Substitute for Fuelwood}

Every society needs energy to ease the chores of everyday living. Energy consumption and pattern of use are good indicators of the level of a community's or country's development. The average energy consumption in the U.S is $90.9 \mathrm{MWh}$ ( $\$ 48000$ GDP per capital); by comparison, that of Brazil is $13.1 \mathrm{MWh}$ ( $\$ 10710$ GDP per capital), while that of Ghana is $4.7 \mathrm{MWh}(\$ 1300$ GDP per capital) (World Resource Institute, 2003; World Bank, 2011; United Nations Statistics Division, 2006). Figure 2 shows energy patterns in Brazil and Ghana (Herltberg, 2003). 

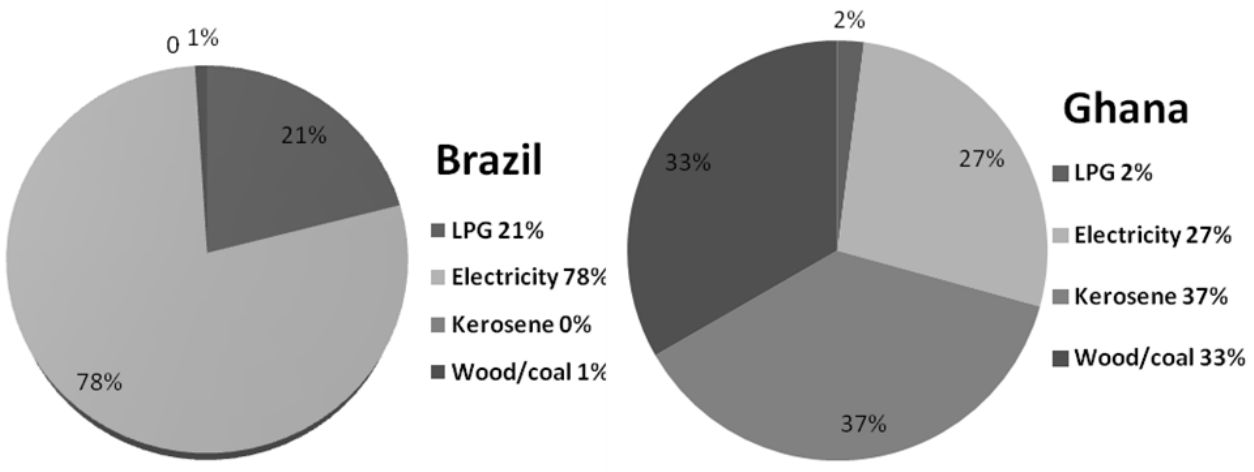

Figure 2. Energy patterns in Brazil and Ghana (Herltberg, 2003)

The current energy needs of developing countries are rather basic, as shown by their use of kerosene and wood/charcoal in Figure 2. According to "the energy ladder", as income increases, wood and charcoal are replaced by kerosene and liquefied petroleum gas (LPG), which, in turn, are eventually replaced by pipe gas or electricity. The percentage of households that use fuelwood cooking in Brazil is $7 \%$, while in Ghana it is $92 \%$ or about 13 times higher (Herltberg, 2003), and this difference is comparable to their relative gross domestic product (GDP) per capital of the two countries. Brazil uses a negligible amount of kerosene for cooking. Fuelwood consumption in Ghana is representative of what is happening in other developing countries, where clean solar energy could be used to replace fuelwood and kerosene usage.

Replacement of fuelwood (and/or kerosene) with solar energy will ameliorate deforestation and environmental degradation concerns in developing countries. Estimated annual consumption of fuelwood is between $750 \mathrm{~kg}$ and $900 \mathrm{~kg}$ per person (Foley, 1985). Five countries - Brazil, China, India, Indonesia, and Nigeria - account for about half the world's fuelwood and charcoal produced and consumed each year. This average fuelwood energy per capital usage is between 7.7 and $9.4 \mathrm{kWh} /$ day (Seifert, 2009).

Fuelwood is dirty, creates domestic pollution (carbon monoxide, soot and particulates), and is slow heating and energy inefficient. As a rule, biomass burns with low efficiencies of only about $10 \%$, or about $15 \%$ for highly efficient stoves. The low burning efficiency gives rise to indoor pollution that leads to health problems of the persons exposed, mostly women, children and the elderly (Ezzati, 2002). According to the World Health Organization (WHO), air pollutants and emissions from burning biomass and coal cause the death of 1.6 million people annually, significantly more than the number of deaths ascribed to malaria (WHO, 2002). Women, who have to bear the household burden of fuelwood gathering, forfeit the opportunity of education and the potential of gainful employment. The unsustainable use of fuelwood is a contributing factor to desertification, which again accelerates the downward poverty spiral. Solar thermal is a win-win for all (Viebahn, 2011). It has zero carbon foot-print, the energy is free, and the energy conversion is about $80 \%$.

\subsection{Solar Energy for Clean Water}

Another equally urgent application for solar thermal is water purification in developing countries. Figure 3 shows the distribution of about $13 \%$ of the world population or nearly 900 million people that are without adequate drinking water (UNICEF, 2008). These millions of people get their drinking water from unsanitary sources like dug wells, springs and surface waters that expose them to water borne diseases like diarrhea, ascaris, hookworm, trachoma (which can cause blindness) or schistomiasis. About 400 children below the age of 5 die per hour in developing countries from waterborne diarrhea alone (Christmas \& de Rooy, 1990; Pruss, 2002). Gleick (2002) also quantified the current and projected consequences of unsafe drinking water. The WHO estimated in 2000 that every eight seconds a child died from a water-related disease and that each year more that five million people died from illnesses linked to unsafe drinking water or inadequate sanitation. The WHO also suggested that if sustainable safe drinking water and sanitation services were provided to all, each year there would be 200 million fewer diarrhea episodes, 2.1 million fewer deaths caused by diarrhea, 150 million fewer schistosomiasis cases, and 75 million fewer trachoma cases. To meet these challenges, the global annual investment in the water and sanitation sector in developing countries was estimated to be about $\$ 10$ billion (U.S.) in the 1990s. On average, $65 \%$ of this funding was raised from in-country resources, the rest from external funding (Christmas \& de Rooy, 1990). CST can be used to significantly reduce the problem and the global investment in providing safe drinking water. 


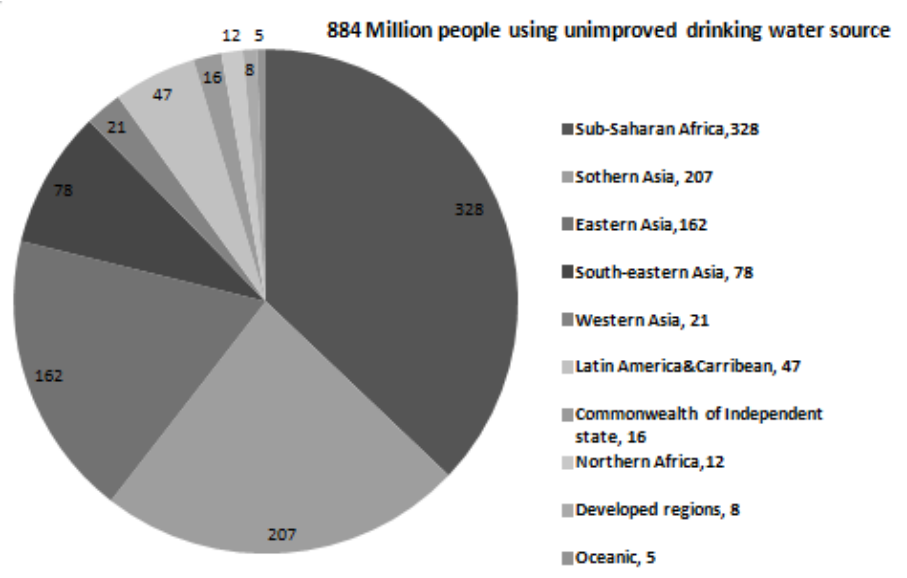

Figure 3. The 884 million people using unimproved drinking water source (UNICEF, 2008)

Several treatment options are used to provide safe drinking water in developing countries. Examples, some of which are also used in combination, include filtration, chlorination, UV treatment, ozone treatment and pasteurization. Pasteurization is the oldest treatment option, where the water is heated to free it from biological contaminants. The other options are cheaper in terms of energy use, but the required chemicals, equipment, and technology are not normally available in these regions. It is not necessary to heat water to boiling to disinfect it. Holding it at a high enough temperature (e.g. 6 minutes at $70^{\circ} \mathrm{C}$ ) is sufficient to pasteurize the water and render it safe. However, the WHO recommends bringing water to a vigorous boil for a few minutes as a fail-safe-method (UNICEF, 2008; Christmas \& de Rooy, 1990). Solar thermal provides a free energy source that will make pasteurization compete favorably with other water treatment options.

\section{Harnessing Methods}

Solar irradiation can be harnessed for heat in many ways and the options are only limited by our imagination and the level of technology in the locality. Open air drying is one of the earliest examples of solar harnessing. Also, plants use solar energy to convert water, air and soil nutrients to grow. The plants can, in turn, be used for energy or food. These examples typify solar thermal in its basic form. Solar thermal is best harnessed if the sun's irradiation is concentrated. High concentration results in higher receiver temperature and the potential of using there covered energy for electricity.

The principle of CSP/CST is illustrated in Figure 4, and the various designs are shown in Figure 5. In all these examples, the concentrator surface intensifies the sun's irradiation by reflecting them on a smaller surface.

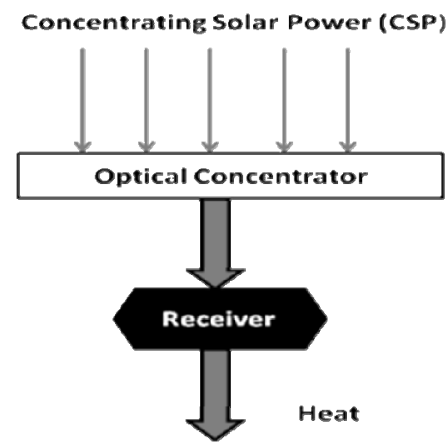

Figure 4. Principle of concentrating solar energy

Four primary CSP designs are on the market today: parabolic troughs (Figure 5b), linear-Fresnel systems (Figure $5 \mathrm{c}$ ), the Stirling engine (Figure 5d), and solar towers (Figure 5e). In parabolic trough systems, each trough has its own receiver, while Fresnel reflectors are made of many thin, flat mirror strips to concentrate sunlight onto common tubes through which a working fluid is pumped. A Stirling dish or dish engine system consists of a stand-alone parabolic reflector that concentrates light onto a receiver positioned at the reflector's focal point. In 
tower systems, thousands of tracking mirrors in a field capture and reflect sunlight to a central receiver atop the tower.
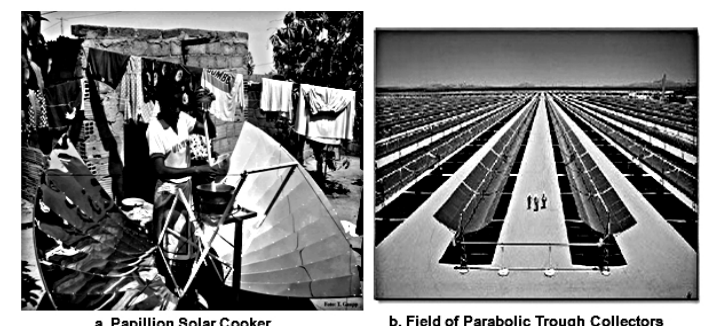

b, Field of Parabolic Trough Collectors
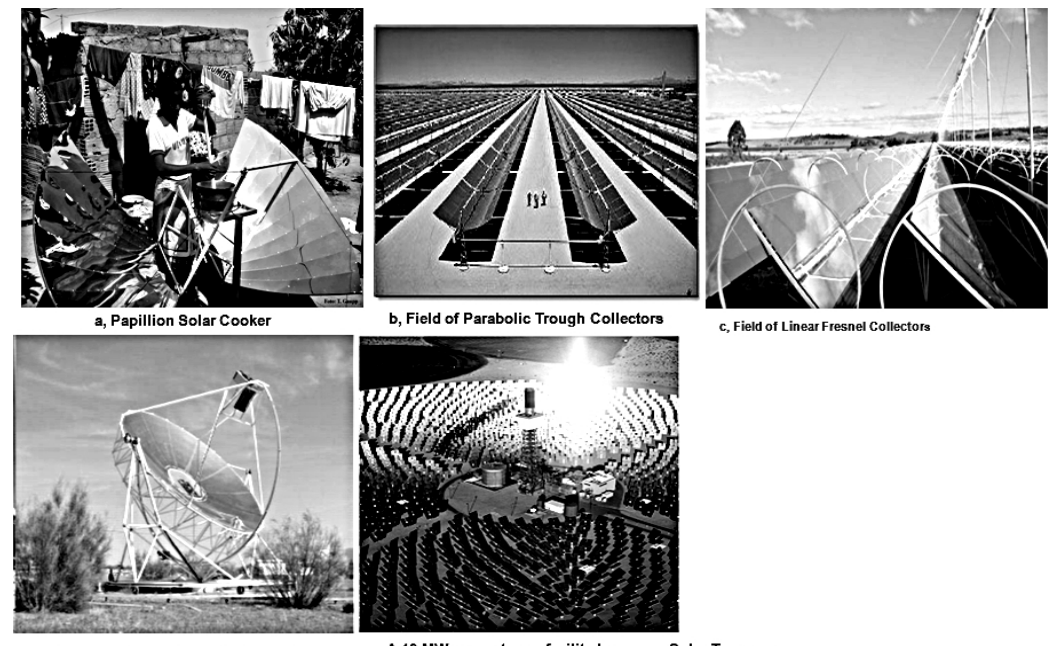

d, Solar Stirling for Electricity Generation

e, A 10-MW power tower facility known as Solar Two near
Barstow, California, with molten salt storage

Figure 5. CSP technologies (Herman-Sanou, 2006; Wolff, 2010)

Our primary focus here is on the parabolic CSP trough system without power generation, PT-CST, because this technology fits well with the special needs of developing countries as a ready source of energy for water treatment and fuelwood substitution.

\subsection{Parabolic Trough Collectors (PT-CST)}

Solar cookers of various designs, including the Papillion (Herman-Sanou, 2006) shown in Figure 5a, were introduced to developing countries to cut down on the use of fuelwood and as sources of clean energy. They were not successful because the cooking must be outdoors when sunshine is available, that is, at a time when the users would rather have been cooking indoors or under the shade. By piping heat transfer fluids through the solar collector, the PT-CST is more practical because the cooking or heating can be done in a house or under a comfortable shade. In addition, these units can be fabricated as standardized modules, which would provide scalability as energy demand changes.

A parabolic trough consists of a linear parabolic reflector that concentrates light onto a receiver positioned along the reflector's focal line. The reflector follows the sun during daylight by tracking along a single axis. A working fluid (e.g., heat transfer fluid or molten salt) is heated as it flows through the receiver and is then used as a secondary heat source. The critical sections of the PT-CST are the parabolic geometry, reflector surface, solar tracker, and thermal storage.
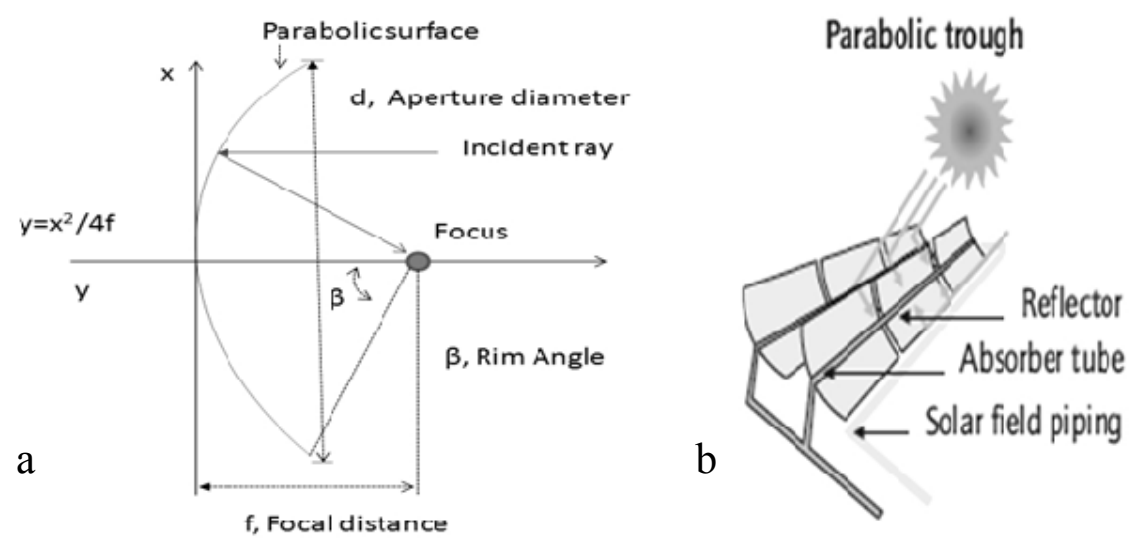

Figure 6. CSP geometric representations 
Figure 6a shows a geometric representation of the cross-sectional area of the parabolic trough, and Figure $6 \mathrm{~b}$ shows the PT-CST assembly. The length of the trough, the aperture diameter $(\mathrm{d})$, and rim angle $(\beta)$ will dictate the amount of heat collection.

The focal length $\mathrm{f}$ is the distance from focal point to the vertex. These parameters can be expressed in the following relationship (Romero-Alvarez \& Zarza, 2007):

$$
\frac{d}{4 f}=\tan \left(\frac{\beta}{2}\right)
$$

The curved cross-section length of the parabola $\mathrm{S}$ is expressed as:

$$
S=\frac{d}{8} \sqrt{\left\{\frac{d^{2}}{f^{2}}+16\right\}}+2 f \sinh ^{-1}\left(\frac{d}{4 f}\right)
$$

As the rim angle $\beta$ increases, the focal length decreases. The power output of the PT-CST depends directly on aperture area, $\mathrm{A}_{\mathrm{a}}$, which is calculated as:

$A_{a}=L d$

where $\mathrm{L}$ is the concentrator's axial length. Another design parameter is the concentration ratio of the parabolic concentrator $\left(\mathrm{C}_{\mathrm{R}}\right)$. This parameter is the ratio of collected radiation intensity to that of the incident radiation, and it is approximated by the geometric concentration ratio, which is the ratio of the aperture area of the concentrator to that of the receiver:

$$
C_{A}=\frac{A_{a}}{A_{r}}=\frac{L d}{\pi d_{o}}
$$

The higher the $C_{R}$, the higher the heated temperature the receiver will be. The theoretical maximum concentration is 215 for a two dimensional collector (Romero-Alvarez \& Zarza, 2007). For the suggested applications here, the working fluid would be oil, the operation temperature would be in the range of $150-400^{\circ} \mathrm{C}$ while the concentration ratio would be in the range 8-80. Water is not recommended as a working fluid because of its high vapor pressure in this temperature range. With a standardized design for fuelwood substitution and water treatment, the parabolic geometry can be provided in the form of preformed flat ribs that can be assembled on site as the background support for the reflecting surface.

\subsection{Concentrator Reflector Surface}

Glass mirrors are the conventional reflector surface materials for CSP. However, mirrors are expensive, heavy, fragile, and not very easy to work. Mirrors are now being replaced with metalized (silver) plastic films. The films are cost-effective and allow for high-volume manufacturing at low item costs. On the low end of these reflectors are multi-purpose Mylar type "mirror films" that will last for about five years. High-end reflectors such as Reflectech film (SkyTrough/NREL) (Reflectech, 2010) and 3M solar film (3M, 2011) are engineered UV-stabilized metalized film with higher reflectance $(>94 \%)$. These materials are lightweight with high mechanical strength and they are designed for prolonged out-door use ( $\sim 20$ years).

\subsection{Solar Trackers}

Solar trackers are devices used to orient photovoltaic panels, CSP concentrators, lenses or other optical devices toward the sun. Since the sun's position in the sky changes with the seasons and the time of the day, trackers are used to align the collection system to maximize energy production. Single axis or dual trackers can be used to keep the sun's image in focus on a linear absorber or receiver. Typically, they are aligned in a north-south orientation to maximize both annual and summer-time energy collection. A single-axis sun-tracking system enables the mirrors to track the sun from east to west during the day. However, a simple PT-CST for water treatment or for cooking can be fitted with a manual tracker, as implemented in the Saracon Solar project in India (Saracon Solar, 2009).

\subsection{Thermal Storage}

PT-CST performance and power can be increased three fold or more if the assembly is designed to include thermal storage. The energy into the storage device can be generated from built-in excess capacity or from the energy generated when there is no load. A conceptual design of a field configuration is shown in Figure 7. 


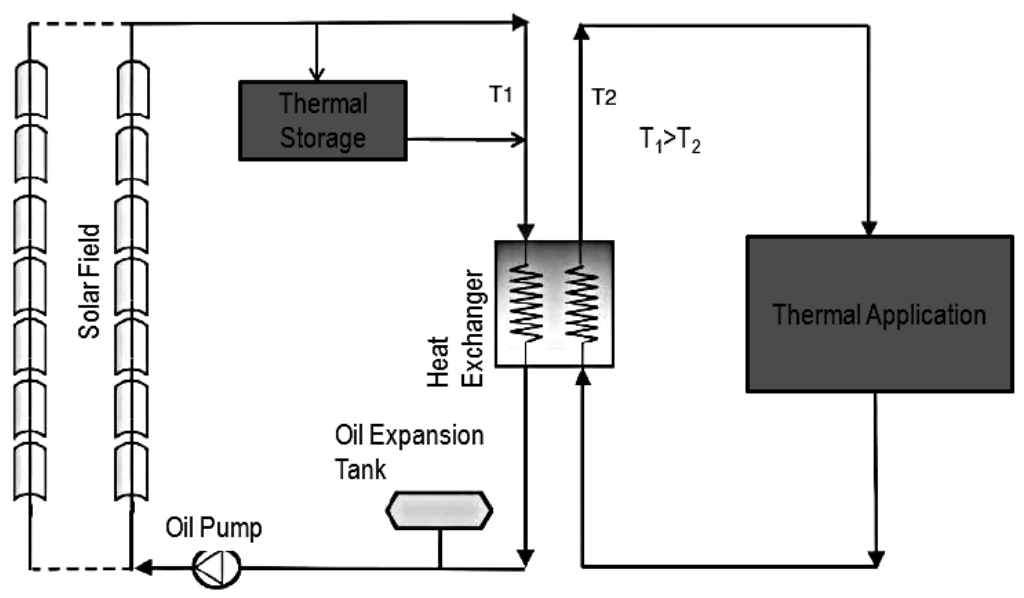

Figure 7. Concept of CSP field design

The thermal storage is the energy source when sunlight is not available (cloudy days, nights, rainy days, etc.). Heat transfer fluids and molten salts have been suggested for CSP thermal storage in the developed world. The German Aerospace Center has proposed a low cost solid-storage method (Tamme, 2003), and this technology can be adapted for developing countries. In this method, heat transfer fluid passes through an array of pipes imbedded in a solid medium (concrete, ceramic, or pebbles), as shown in Figure 8, to transfer the thermal energy to and from the media during operations. This type of storage could be built on-site from local resources and manpower, and the capacity could be increased as needed.

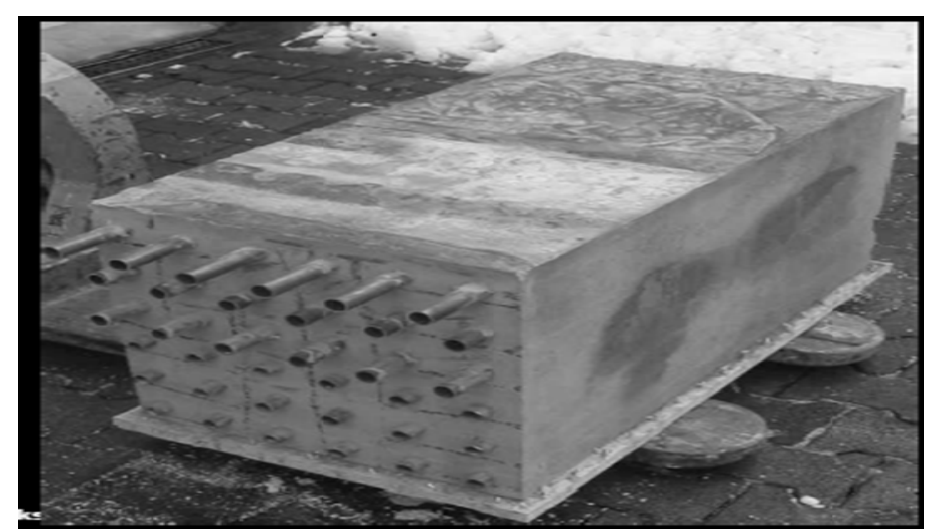

Figure 8. The German Aerospace Center (DLR) concrete for CSP-thermal storage (Tamme, 2003)

\subsection{Nominal Duty Requirements}

The duty estimation of the PT-CST is based on the energy requirements for fuelwood substitution or the energy required to process enough water for a household. Based on the average fuelwood consumption in developing countries and the efficiency of fuelwood conversion, a household of five will need about $12 \mathrm{kWh} /$ day of solar thermal energy to replace its fuelwood consumption. For a DNI average of $5.0 \mathrm{kWh} / \mathrm{m}^{2} /$ day, a PT-CST with aperture of about $3 \mathrm{~m}^{2}$ has more than adequate capacity to replace fuelwood for most households in developing countries.

For safe water usage in a household, Gleick recommended a basic water requirement (BWR) per person of 50 liters per day (Gleick, 1966). This estimation covers the minimum water for drinking, sanitary services, bathing and cooking. Industrialized countries use 500-800 liters of water per person/day, which is about ten times more than the recommended minimum. Gleick also reported that water usage in most developing countries is below the recommended minimum BWR and the availability of PT-CST will solve this deficiency problem. The source water will be pasteurized by heating and bringing the water to boiling and maintaining it at that temperature for about six minutes. The energy requirement is about $30 \mathrm{kWh} /$ day. A PT-CST with an aperture area of $7.5 \mathrm{~m}^{2}$ that 
will produce $37.5 \mathrm{kWh} /$ day will be more than sufficient.

The conservative estimation also suggests that a trough of $7.5 \mathrm{~m}^{2}$ aperture area can be used for both cooking and the pasteurization of all the basic water requirements (2 500 liters) for a family of five. For hospitals and health centers these units will have additional capacities to sterilize instruments and medical devices.

\subsection{Cost of PT-CST}

Since solar power units do not use any fuel, the total cost consists primarily of capital cost with minor operational and maintenance costs. If the lifetime of the unit or assembly and the interest rate are known, the cost per kWh, or "levelized energy cost", can be calculated. The cost of PT-CST could be made affordable if the design is standardized and templates are made available for those in developed countries. Other critical materials like reflector films, solar trackers, and valves could be packaged for each modular unit. With modular CST, families or communities that need more energy than that of a single module could use multiple modules. The modularity allows for onsite assembly to reduce operational and maintenance costs. Replaceable parts would also be made available among the user community within a very short period, and a knowledge base about the technology would rapidly be created among users.

\section{Technology Dissemination}

Solar energy is clean and non-polluting, and contributes no greenhouse gas emissions. The goal is to convince developing countries to embrace solar technology as soon as possible, and CST for fuelwood replacement and water treatment will help to launch this technology.

Although solar thermal is a mature technology in developed countries, the concept is new to developing countries, and we expect the usual inertia and reluctance that often precede radical changes. Institutions like schools, hospitals, health centers, and market centers would likely be more amenable to such changes because of their group support and diverse resources.

It is thus best to start the dissemination of PT-CST through these institutional groups. Schools and hospitals in developing countries do not have assured access to good safe water, and that invariably puts children and patients at risk of waterborne diseases. Students and women spend hours every day searching for fuelwood. These groups already appreciate the urgency and the benefits of having clean and safe drinking water, and they would more likely embrace this technology. In addition, they have the resources to support the challenges of a new technology. Since PT-CSP is modular, each group could add as many units as needed to meet its energy requirements for fuelwood or water purification. A successful implementation with these institutional groups would be a showcase for individual families that have children in schools and patronize the hospitals and markets to embrace this technology.

\section{Conclusions and Recommendations}

There is a continuing effort to harness the abundant supply of solar irradiation for power. CSP for electricity generation is being implemented in developed countries at a rapid pace. Developing countries need to join this effort, with the initial focus being on employing solar energy to solve their fundamental problems such as an energy source to replace fuelwood and energy for preparing safe drinking water. CST is a one-time affordable investment that offers a long-term solution to fuelwood usage and its disastrous effects such as deforestation, greenhouse emission, and indoor pollution in developing countries. Energy from CST as described here is a cheaper and appropriate alternative for treating water for safe drinking in poor regions where millions of people are without adequate drinking water.

A standardized modular CST design for fuelwood replacement and drinking water treatment is recommended. The same design could be used for both purposes, and the design should be flexible to allow for onsite assembly to reduce cost and promote local input. Widespread adaptation of the technology likely will require support from in-country resources, as well as external funding. If successful, this technology could reduce global desertification, greenhouse emissions, and global expenditure on diseases from unsafe drinking water for nearly 900 million people.

\section{Acknowledgment}

The submitted manuscript has been created by Argonne National Laboratory, a U.S. Department of Energy laboratory managed by UChicago Argonne, LLC, under Contract Number DE-AC02-06CH11357. The U.S. Government retains for itself, and others acting on its behalf, a paid-up nonexclusive, irrevocable worldwide license in said article to reproduce, prepare derivative works, distribute copies to the public, and perform publicly and display publicly, by or on behalf of the Government. 


\section{References}

3M. (2012). Solar Mirror Film 1100 application guide. Retrieved from http://multimedia.3m.com/mws/mediawebserver?mwsId=66666UuZjcFSLXTtnxMEmXfcEVuQEcuZgVs6 EVs6E666666--\&fn=SMF1100AppGuideline_DMR.pdf

Christmas, J., \& de Rooy, C. (1990). The decade and beyond: At a glance. New York: UNICEF Water Sanitation Sector, Program Division.

Cohen, G. E., Kearney, D. W., \& Price, H. W. (1999). Performance history and future costs of parabolic trough solar electric systems. Journal de Physique IV, France, 9(3), 169-179. http://dx.doi.org/10.1051/jp4:1999326

Ezzati, M., \& Kammen, D. M. (2002). The health impacts of exposure to indoor air pollution from solid fuels in developing countries: knowledge, gaps, and data needs. Environmental Health Perspectives, 110(11), 1057-1078. http://dx.doi.org/10.1289/ehp.021101057

Foley, G. (1985). Wood fuel and conventional fuel demands in the developing world. Ambio, 14, 253-258.

Gleick, P. H. (1966). Basic water requirements for human activities. Water International, 21, 83-92. http://dx.doi.org/10.1080/02508069608686494

Gleick, P. H. (2002). Dirty Water: Estimated Deaths from Water-Related Disease 2000-2020. Oakland, CA: Pacific Institute.

Heltberg, R. (2003). A household fuel and energy use in developing countries: A multi-country Study,World Bank, Oil and Gas Policy Division, May 14.

Hermann-Sanou, M. (2006). Evaluation of 3 solar cooker projects in Burkina Faso/West Africa, Granada Solar Cooking Conference. Retrieved from http://www.docstoc.com/docs/30651874/evaluation-of-3-solar-cooker -projects-in-burkina-faso

Knies, G. (2012). DESERTEC Foundation, Ferdinandstr, Hamburg, Germany. Retrieved from http://www.desertec.org

Montgomery, M. A., \& Elimelech, M. (2007). Waterand sanitation in developing countries: includinghealth in the equation. Environmental Science \& Technology, 41, 17-24. http://dx.doi.org/10.1021/es072435t

Prüss, A., Kay D., Fewtrell, L., \& Bartram, J. (2002). Estimating the burden of disease from water, sanitation, and hygiene at a global level. Environmental Health Perspectives, 110(5), 537-542. http://dx.doi.org/10.1289/ehp.02110537

ReflecTech. (2010). Mirror film fact sheet. Retrieved from http://www.reflectechsolar.com/pdfs/TechnicalData\%28ReflecTech\%29.pdf

Romero-Alvarez, M., \& Zarza, E. (2007). Concentrating solar thermal power. Handbook of energy efficiency and renewable energy. Boca Raton, FL: CRC Press.

Sambo, S. (2008). Electricity demand from customers of INGA hydropower projects: The case of Nigeria.WEC Workshop on Financing INGA Hydropower Projects, April 21 and 22, 2008, London, U.K. Retrieved from http://www.ffydd.org/documents/abubakar_sambo_final.pdf

Sawin, J. L., \& Martinot, E. (2011). Renewables bounced back in 2010, finds REN21 global report. Renewable Energy World, September.

Seifert, R. D. (2009). Heating value of fuels. University of Alaska Fairbanks Cooperative Extension Service, EEM-04253.

Solar Coolers World Network. (2009). $\quad$ Retrieved from http://solarcooking.wikia.com/wiki/Saracon_Solar_Cooker.

Solar and Wind Energy Resource Assessment. (2005). Retrieved from http://swera.unep.net/typo3conf/ext/metadata_tool/archive/download/africatilt_218.pdf

Tamme, R. (2003). Concrete Storage: Update on the German concrete TES program. Workshop on Thermal Storage for Trough Power Systems, February 20-21, Golden, CO.

UNICEF and World Health Organization. (2008). Progress on drinking water and special focus on sanitation. WHO/UNICEF Joint Monitoring Programme for Water Supply and Sanitation. Retrieved from http://www.who.int/water_sanitation_health/monitoring/jmp2008/en/index.html

United Nations Statistics Division. (2006). 2006 Energy Statistics Yearbook. Retrieved from 
http://unstats.un.org/unsd/pubs/gesgrid.asp?id=40

Viebahn, P., Lechon, Y., \& Trieb, F. (2011). The potential role of concentrated solar power (CSP) in Africa and Europe-A dynamic assessment of technology development, cost development and life cycle inventories until 2050. Energy Policy, 39(8), 4420-4430. http://dx.doi.org/10.1016/j.enpol.2010.09.026

Wolff, G. (2010). The Desertec concept: Clean power from deserts. Renewables 2010 Conference, Marketforce and Institute of Economic Affairs, July 7-8.

World Bank Report. (2011). World development report 2011: Conflict, security, and development. Retrieved from http://wdr2011.worldbank.org/

World Health Organization. (2000). Global Water Supply and Sanitation Assessment 2000 Report. Retrieved from http://www.who.int/water_sanitation_health/Globassessment/GlobalTOC.htm

World Health Organization. (2002). The world health report 2002: Reducing risks, promoting healthy life. Retrieved from http://www.who.int/whr/2002/en

World Resources Institute Annual Report. (2003). Ideas into action: working at the intersection of environment and human needs. Retrieved from http://www.wri.org/publication/wri-annual-report-2003 